\title{
DE LAS LUCHAS POR UNA NUEVA LEY DE MIGRACIONES AL PARO MIGRANTE. NUEVAS CONFIGURACIONES DE LAS LUCHAS MIGRANTES EN ARGENTINA
}

\author{
From the struggles for a new migration law to the Migrant Strike. \\ New configurations of migrating struggles in Argentina
}

Resumen. Este artículo propone un estudio de las nuevas configuraciones que asumen las luchas migrantes en Argentina entre los años 2016 y 2019. El surgimiento de organizaciones de migrantes, como el Bloque de Trabajadorxs Migrantes (BTM), y el impulso de espacios de articulación, como la Campaña Migrar no es Delito (CMND), imprimen nuevas características al campo político de la migración en Argentina. El análisis se orienta a describir y analizar las visiones, demandas, estrategias, estructuras de organización y los vínculos que estas organizaciones mantienen con el Estado. La metodología es de carácter cualitativo en el análisis de declaraciones y de registros de campo en movilizaciones y actividades públicas del BTM y la CMND.

Palabras calaves: luchas migrantes; Argentina; políticas de control migratorio.

\begin{abstract}
This article proposes a study of the new configurations that migrating struggles assume in Argentina between the years 2016 and 2019. The emergence of migrant organizations, such as the Bloque de Trabajadorxs Migrantes (BTM), and the impulse of articulation spaces, such as the Campaña Migrar no es Delito (CMND), they print new characteristics to the political field of migration in Argentina. The analysis is oriented to describe and analyze the visions, demands, strategies, organizational structures and the relations that these organizations maintain with the State. The methodology is qualitative in the analysis of declarations and field records in mobilizations and public activities of the BTM and the CMND.
\end{abstract}

Keywords: migrating struggles; Argentina; migration control policies.

Centro de Investigaciones y Estudios sobre Cultura y Sociedad (CONICET y UNC). Córdoba, Argentina. E-mail: mgabrielarho@gmail.com. Orcid:0000-0003-0959-2877. 


\section{Introducción}

Este trabajo propone realizar un estudio de las nuevas configuraciones que asumen las luchas migrantes en Argentina entre los años 2016 y 2019 . El impulso de políticas migratorias que incrementan y recrudecen los elementos de control y la violencia estatal sobre la población migrante y la circulación de discursos criminalizantes y xenófobos, habilitaron la emergencia de novedosas formas de organización, movilización y participación de los migrantes, que trazaron un escenario inédito en la configuración de las luchas migrantes. El surgimiento de organizaciones de migrantes, como el Bloque de Trabajadorxs Migrantes (BTM), y el impulso de espacios de articulación, como la Campaña Migrar no es Delito (CMND), imprimen nuevas características al campo político de la migración en Argentina.

Para comprender la configuración particular de las luchas migrantes en la actualidad es necesario pensarlas desde su historicidad, es decir, las luchas migrantes actuales se conforman no solo a partir de las condiciones específicas de la realidad en la que surgen sino también de las dinámicas y estrategias que proceden de procesos de organización de los migrantes en el pasado. A su vez, requiere ponerlas en diálogo y pensarlas en relación al contexto de luchas más amplio ya que las visiones y estrategias desplegadas por las organizaciones de y para migrantes se entrelazan con las de diversos movimientos sociales de Argentina, como son por ejemplo, el movimiento de derechos humanos y los movimientos sociales de trabajadores desocupados y excluidos. Es así que, para analizar las trasformaciones en el campo de las luchas migrantes en Argentina es necesario considerar y hacer dialogar tres procesos: las experiencias políticas organizativas, que desde mediados de los años noventa vienen llevando adelante organizaciones de y para migrantes; el surgimiento de nuevas formas de organización de la mano de jóvenes migrantes e hijos de migrantes y los cambios que se producen en los movimientos sociales constituidos por organizaciones de trabajadores desocupados y excluidos.

En este sentido, las luchas migrantes que comienzan a desarrollarse a partir del año 2016 presentan elementos novedosos respecto a las luchas que, desde mediados de los años noventa, despliegan organizaciones de migrantes, los organismos de derechos humanos y de asistencia social a migrantes. Como se intentará mostrar éstas reconfiguraciones responden a que las luchas migrantes no solo se van a inscribir en el marco general de las luchas llevadas adelante por el movimiento de derechos humanos o de las organizaciones de migrantes más tradicionales, sino que también van a entrar en diálogo con las tradiciones políticas de las organizaciones sociales de trabajadores desocupados y excluidos y las experiencias políticas de los jóvenes migrantes e hijos de migrantes. Este doble proceso transforma las estructuras de organización, las estrategias de 
protesta y pone en cuestión las visiones y los vínculos que organizaciones como el BTM y la CMND establecen con el Estado.

En términos teóricos, se recuperan los aportes de la autonomía de las migraciones, la cual entiende que la gestión y control de las migraciones ocupan un papel estratégico en la constitución del capitalismo y en la sujeción de la mano de obra al capital, lo que implica que la migración siempre se encuentra atravesada por e involucrada en múltiples y heterogéneas luchas. Las migraciones se inscriben dentro de un campo de luchas conflictivo donde la modificación y la disputa por la definición y los sentidos de las políticas de control y gestión de las migraciones siempre están en juego (Mezzadra, 2012, p. 164; De Genova, Mezzadra, Pickles, 2015, p. 81). Las luchas migrantes son parte constitutiva de este campo y un factor activo y creativo debido a que las políticas de control y gestión de las migraciones se organizan y reconfiguran a partir de los modos en que son interpeladas por las transformaciones que adquieren los movimientos migratorios y por las luchas que se derivan de ellos. Por lo que las luchas migrantes necesariamente se encuentran articuladas a políticas y prácticas de control y vigilancia de la migración (Domenech, Boito, 2019, p. 161-162). En este marco, se entienden a las luchas migrantes como aquellas "luchas más o menos organizadas en las que los migrantes abiertamente desafían, derrotan, evaden o dificultan las políticas dominantes de la movilidad (incluyendo el control fronterizo, la detención y la deportación), o el régimen de trabajo o el espacio de ciudadanía" (De Genova, Mezzadra, Pickles, 2015, p. 80).

En este trabajo, se analizan estructuras organizativas, estrategias de reclamo y acciones colectivas protagonizadas por organizaciones de y para migrantes que se articulan con el fin de conseguir la movilización política reivindicativa en relación a discursos, prácticas y políticas que criminalizan y afectan a los migrantes, como son, el aumento de los controles y restricciones para la circulación y regularización y la vulneración y quita de derechos. Ante la multiplicidad de formas que pueden asumir las luchas migrantes, se consideran aquellos procesos de organización que buscan ser visibles en el espacio público y entablar mecanismos de confrontación, diálogo o negociación con las instituciones estatales encargadas del control y gestión de la migración. Es central realizar la distinción entre organizaciones de y para migrantes debido a que entre uno y otro tipo de asociaciones no solo difiere la composición interna sino también sus áreas y modalidades de actuación, su continuidad histórica y sus redes de relaciones lo que conduce a variadas formas de articulación, colaboración y tensión (Caggiano, 2011, p. 50). De acuerdo a Caggiano (2011), las organizaciones para migrantes son aquellas que sin estar integradas o haber sido impulsadas por inmigrantes toman los derechos de éstos como su razón de ser o como una de sus áreas de acción prioritarias; y las organizaciones 
de migrantes, las que están conformadas por los propios migrantes (Caggiano, 2011, p. 50).

Respecto a la metodología, se utilizó un enfoque cualitativo que combinó técnicas como el análisis documental y la observación participante. Para la elaboración del corpus documental se sistematizaron pronunciamientos, documentos de trabajo y declaraciones resultantes de los encuentros, reuniones y actividades desarrolladas, entre los años 2016 y 2019, por el BTM y la CMND. En relación con la observación participante se realizaron registros de campo de diversas actividades públicas del BTM y la CMND como son asambleas abiertas, movilizaciones, actos públicos y actividades de formación. Del mismo modo, se registraron, a través de las redes sociales (Facebook), actividades que fueron transmitidas en vivo. En este sentido, se observaron conferencias de prensa, actos públicos y movilizaciones. El registro de la información obtenida a través de las redes sociales incluyó la transcripción y la sistematización de fotografías, videos, spots y folletos de difusión de las actividades. Es importante señalar que el trabajo se centra en los procesos organizativos ocurridos en la ciudad de Buenos Aires.

El artículo se estructura en dos apartados: en primer lugar, a partir de la revisión de la bibliografía existente se reconstruirán las luchas desarrolladas, desde mediados de los años noventa, por las organizaciones de y para migrantes orientas a la derogación de la Ley 22.439 (Ley Videla). Recuperar el proceso de surgimiento y las formas que asumen estas luchas se considera fundamental para comprender las reconfiguraciones que se producen en la actualidad. En segundo lugar, se presentarán algunas hipótesis de trabajo que buscan, por un lado, identificar los procesos políticos que habilitan el surgimiento de nuevas organizaciones migrantes (BTM) y espacios de articulación (CMND) y, por otro lado, avanzar en la caracterización de las luchas migrantes desplegadas a partir del año 2016. En el intento de identificar los elementos inéditos presentes en estas luchas se analizarán las visiones, las demandas, las estrategias de reclamo, las estructuras de organización y los vínculos que establecen con el Estado el BTM y la CMND.

\section{Las luchas por una nueva ley de migraciones}

A mediados de los años noventa comienzan a visualizarse las primeras acciones de organizaciones de y para migrantes que van a constituirse en experiencias de organización política centrales para comprender las transformaciones de las luchas migrantes en la actualidad. Estas acciones de protesta surgieron contra las políticas migratorias restrictivas y el aumento de la violencia, la persecución policial y la xenofobia del gobierno nacional que buscaba convertir a los migrantes en un "chivo expiatorio" del fracaso de las políticas de ajuste y reestructuración neoliberal (Grimson, 2006, p. 81-82). 
En el año 1996, organizaciones de migrantes, de derechos humanos, de asistencia a migrantes y refugiados, sindicatos, instituciones eclesiásticas y centros de investigación comenzaron a reunirse y, en el año 2000, constituyeron formalmente la Mesa de Organizaciones de la Sociedad Civil en Defensa de los Derechos de los Migrantes. Entre las organizaciones que la impulsaron se encuentran el Servicio de Apoyo y Orientación Ecuménica a Inmigrantes y Refugiados (CAREF), la Fundación de la Comisión Católica de Migraciones (FCCAM), el Centro de Estudios Legales y Sociales (CELS), la Asamblea Permanente por los Derechos Humanos (APDH), el Departamento de Migraciones de la Central de Trabajadores Argentinos (CTA), el Centro de Estudios Migratorios Latinoamericanos (CEMLA), el Departamento de Migraciones del Arzobispado de Buenos Aires, la Red de Investigadores de Migraciones Contemporáneas (RIMCA) y el Servicio de Paz y Justicia (SERPAJ) (Correa, 2006, p. 5).

El protagonismo que asumieron en la Mesa los organismos de derechos humanos y las organizaciones de asistencia social y jurídica a migrantes impactó en las demandas y las visiones que se adoptaron, como así también, en las estrategias y vínculos que se establecieron con los organismos e instituciones del Estado encargadas de la migración. En primer lugar, las demandas de la Mesa se centraron en exigir la derogación de la ley de migraciones (Ley 22.439) y sus acciones apuntaron a la sanción de una nueva normativa migratoria. Derogar la Ley Videla suponía "derogar una ley de la dictadura" (Correa, 2006, p. 7), como así también, se consideraba una solución de fondo para los casos individuales que atendían las organizaciones (Pereira, 2017, p. 155).

En segundo lugar, las visiones de la Mesa se enmarcaron en un enfoque de derechos humanos ya que muchas de estas organizaciones, en los años ochenta, asumieron un rol central en los debates tendientes a la construcción de un nuevo orden democrático. Esto condujo a que se instalé en la esfera pública un nuevo marco interpretativo que ponía énfasis en la defensa de los derechos humanos (Jelin, 2006, p. 59). En los años noventa estas preocupaciones se redefinieron en función de las nuevas realidades de exclusión y polarización social, lo que llevó a recuperar y reintegrar estos temas -incluida la cuestión migrante- a las lógicas de los derechos humanos y la participación ciudadana (Jelin, 2003, p. 13). Así, las prácticas de estas organizaciones se orientaron a defender los derechos humanos de los migrantes y construirlos como sujetos de derecho frente a los discursos xenófobos.

En tercer lugar, el contexto de surgimiento de las organizaciones de la Mesa marcó las formas de construir y hacer política, centralmente, en relación a los vínculos que se establecieron con el Estado. La participación en los debates en torno a la "transición democrática" supuso el abandono del paradigma del cambio social mediante una revolución, lo que llevó a valorizar a la democracia 
liberal como un régimen político institucional capaz de garantizar derechos humanos (Alonso, 2008, p. 88). Esto trajo como correlato que se apueste a una forma instituyente de hacer política, es decir, estas organizaciones construyeron como horizonte político la generación de demandas y acciones capaces de traducirse dentro de marcos políticos institucionales. En el afán de construir y fortalecer las instituciones democráticas, los espacios estatales institucionalizados se convirtieron en las instancias valorizadas para articular y encausar sus luchas.

De este modo, en cuarto lugar, las organizaciones de la Mesa privilegiaron una estrategia de trabajo en conjunto y en dialogo con organismos estatales e internacionales vinculados a la migración, no solo a fin de que se derogue la Ley Videla sino también para que se sancione una nueva ley de migraciones. Así, se optó por la coordinación de acciones con diputados y senadores progresistas que ya trabajaban en proyectos para una nueva política migratoria (Pereira, 2017, p. 156; Baradó, 2006, p. 219). Igualmente, se intervino en organismos internacionales vinculados a la defensa de los derechos humanos como La Comisión Interamericana de Derechos Humanos (CIDH). Ésta se utilizó como una instancia de presión al Estado argentino para que incorpore a la normativa migratoria los estándares internacionales de derechos humanos (Mardones, 2005, p. 26). A su vez, el perfil de asistencia social y de asesoramiento judicial a migrantes de estas organizaciones supuso la articulación con instituciones estatales como el Instituto Nacional contra la Discriminación, la Xenofobia y el Racismos (INADI) y la Defensoría de la Ciudad Autónoma de Buenos (Baradó, 2006, p. 213).

En último lugar, una característica central de la Mesa es que se constituyó como un espacio de articulación entre organizaciones para migrantes (Pereira, 2017, p. 153). Las colectividades y asociaciones de migrantes conformaron en el año 2003 su propio espacio de articulación: la Coordinadora de Colectividades de Inmigrantes. A pesar de que la derogación de la Ley Videla era una demanda que atravesaba su conformación, se privilegió abordar las dificultades que suponía la regularización migratoria. Mediante dos movilizaciones se reclamó al Estado un pedido de amnistía (Mardones, 2005, p. 33). Lo cierto es que la derogación de la Ley Videla fue la demanda que tomó mayor centralidad, de modo que los organismos de derechos humanos y de asistencia social fueron los que asumieron la conducción de las luchas ya que, el abordaje legal y técnico que suponía esta demanda, colocó a los "especialistas" de estas organizaciones (principalmente abogados e investigadores universitarios) en un rol central y como interlocutores "capacitados" para llevar adelante los debates en los espacios de negociación institucional.

En diciembre de 2003 se deroga la Ley Videla y se aprueba una nueva ley de migraciones, la Ley 25.871. Esto produce cambios significativos ya que se 
amplía el reconocimiento de derechos a migrantes ${ }^{1}$, se impulsan programas de regularización y se modifica el discurso de los funcionarios estatales, que dejan atrás expresiones abiertamente xenófobas a través de lo que se denominó una "retórica de la inclusión", asentada en los derechos humanos, la integración de los migrantes y fundada en la noción de "aporte" económico y cultural de la migración (Domenech, 2010, p. 26).

Las luchas desplegadas en los años noventa tuvieron gran centralidad en la sanción de la nueva Ley de Migraciones, por lo que estas experiencias de organización van a dar forma y definir las características que asume, en términos generales, el campo político de las luchas migrantes hasta el año 2016. La centralidad que asumió la sanción de una nueva ley de migraciones en el año 2003 va a dejar una fuerte impronta en las visiones y las estrategias con las que se articularon las acciones en torno a la cuestión migrante. En este sentido, por un lado, para estas organizaciones la ley de migraciones se convirtió en una bandera de defensa de los derechos humanos de los migrantes. Domenech y Boito (2019) sostienen que se consolida el lenguaje de los derechos humanos pero desde una perspectiva institucionalizada donde éstos se convirtieron en un asunto técnico y se redujeron a su abordaje legal. Así, se afianza una visión legalista ya que las luchas de estas organizaciones giraron en torno a la denuncia de las deficiencias e irregularidades en la implementación de la ley o de los planes de regularización, centrando sus acciones en cuestionar aquellos casos en los que no eran respetadas las garantías judiciales y los procedimientos instituidos por ley (Domenech, Boito, 2019, p. 182)².

Por otro lado, las trasformaciones del discurso estatal y el impulso de políticas de ampliación de derechos fortalecieron los vínculos que muchas organizaciones habían establecido con diversas instituciones estatales encargadas de la migración, reforzando las vías institucionales en la canalización de sus demandas. El Estado argentino se reposiciona a nivel regional y mundial

1 La Ley 25.871 reconoce el derecho a migrar como derecho humano, el derecho a la reunificación familiar, al acceso a la salud y la educación sin perjuicio de la condición migratoria, el derecho al debido proceso en situaciones de detención y expulsión e incorpora medidas que facilitan la regularización al flexibilizar los criterios de radicación (Courtis, Pacecca, 2007, p. 10).

2 Esto no impidió que se cuestionen medidas como el establecimiento de un nuevo instructivo para detectar "falsos turistas" (que habilita los rechazos en frontera a aquellas personas que se "sospeche" busquen ingresar o permanecer en el país con otras finalidades) y las reformas del Código Procesal Penal de la Nación (que introduce, a través del artículo 35, la expulsión de extranjeros). Éstas generaron mayor repercusión y fueron cuestionadas a través de declaraciones públicas por organizaciones como el CELS y la Red de Lideres Migrantes (Domenech, Boito, 2019, p. 183-184). Del mismo modo, se llevaron adelante una serie de procesos organizativos orientados a ampliar los derechos contenidos en la ley de migraciones, como por ejemplo, aquellos orientados al establecimiento de derechos políticos. Por ejemplo, en la Ciudad Autónoma de Buenos Aires se desarrolló en el año 2011 la Campaña "Aquí Vivo, Aquí Voto" y, entre los años 2009 y 2016, se produjeron procesos de organización política de los migrantes en torno el voto en el exterior (Gerbaudo Suárez, Sander, 2017, p. 5-7). 
como un modelo en normativa migratoria, por lo que las organizaciones van a entender a diversas instituciones estatales encargadas de la migración como aliadas estratégicas en la ampliación de los derechos migrantes. A partir de esto no se configura un escenario de confrontación sino más bien de diálogo y trabajo en conjunto (Domenech, Boito, 2019, p. 182 y 171). Por ejemplo, en el año 2008, muchas organizaciones que habían participado de los procesos de sanción de la nueva ley de migraciones formaron parte de la Comisión Asesora impulsada por el Poder Ejecutivo Nacional -como espacio formal para encausar los debates en torno a su reglamentación- desde la cual se elaboró un documento que, en el año 2010, fue aprobado como texto reglamentario de la Ley 25.871 (CELS, 2011, p. 28). La creación de la Mesa de Diálogo Migratorio en el año 2014 -conformada para formalizar las discusiones vinculadas a las políticas públicas en materia migratoria y evaluar las políticas implementadas en el marco de la ley 25.871- es la consolidación de la relación que estas organizaciones mantienen con la DNM (Domenech, Boito, 2019, p. 181; Canelo, Gavazzo, Nejamkis, 2018, p. 160).

\section{Nuevas configuraciones de las luchas migrantes}

El escenario político que se abre en 2015 con la asunción del gobierno de Cambiemos, habilita el surgimiento de nuevas organizaciones y espacios de articulación de migrantes que transforman las configuraciones de las luchas migrantes. El impulso de políticas migratorias concebidas como parte de las políticas de seguridad incrementaron los elementos de control, criminalización y violencia estatal sobre la población migrante. En esta línea, para justificar el recrudecimiento de las políticas migratorias, se acudió a la difusión de datos presentados de manera engañosa que buscaban asociar a los migrantes con la inseguridad ciudadana, la delincuencia organizada y el narcotráfico. Medidas como el incremento de los operativos de control y permanencia y de las disposiciones de expulsión; la creación de la Comisión Nacional de Fronteras; el requisito de certificar 10 años sin antecedentes penales para radicarse en el país y la firma de un convenio por el cual la Policía de la Ciudad de Buenos Aires se suma como policía migratoria auxiliar, apuntaron a aumentar los controles para el ingreso de extranjeros con antecedentes penales y acelerar los mecanismos para expulsarlos del país. A esto se le suman medidas que se dirigieron a dificultar los procesos de regularización, como el aumento de un $1000 \%$ del costo de las tasas migratorias; el establecimiento del Radex como un nuevo sistema de radicación online a distancia; la demora en los turnos para realizar los trámites de regularización, entre otras (Canelo, Gavazzo, Nejamkis, 2018, p. 162; Penchaszadeh, García, 2018, p. 97-98).

El anuncio de la creación de un Centro de Detención para infractores de la Ley Nacional de Migraciones, en agosto de 2016, fue lo que generó 
mayor visibilidad pública y lo que alentó las primeras manifestaciones. Junto con declaraciones públicas de rechazo al Centro de Detención, migrantes, organizaciones de asistencia a migrantes y organismos de derechos humanos, realizaron movilizaciones frente al edificio designado para ello (Canelo, Gavazzo, Nejamkis, 2018, p. 168). El punto de inflexión se produce en el año 2017 con la sanción del Decreto de Necesidad y Urgencia 70/2017 (DNU 70 ), debido a que modifica aspectos sustanciales de la Ley de Migraciones $\mathrm{N}^{\circ}$ $25.871^{3}$.

Los organismos de derechos humanos y de asistencia a migrantes fueron los primeros en responder al DNU 70 mediante el despliegue de estrategias legales y de presión institucional. Por un lado, CELS, CAREF y el Colectivo por la Diversidad (COPADI) elaboraron un recurso de amparo que denunciaba su inconstitucionalidad y solicitaba su nulidad. Por otro lado, el CELS convocó a una reunión para delinear acciones que permitan frenar la promulgación del DNU en la Comisión Bicameral Permanente ${ }^{4}$. De estas reuniones se formó una comisión multisectorial que se propuso actuar en conjunto en la Comisión Bicameral y mantener reuniones con los senadores que podían frenar el DNU en esta instancia (Canelo, Gavazzo, Nejamkis, 2018, p. 171). Del mismo modo, se recurrió a organismos internacionales de derechos humanos. En una audiencia ante la CIDH, en marzo de 2017, referentes del CELS, de CAREF, de la Unión de Colectividades de Inmigrantes de Córdoba, la Red de Lideres Migrantes y del Instituto Argentino para la Igualdad, Diversidad e Integración (IARPIDI), denunciaron la inconstitucionalidad del DNU (Canelo, Gavazzo, Nejamkis, 2018, p. 170).

En paralelo a las acciones desplegadas por los organismos de derechos humanos y las organizaciones de migrantes, se fueron gestando nuevos espacios políticos de articulación que reconfiguran el escenario de las luchas migrantes en Argentina. Estos espacios se gestan en las movilizaciones en rechazo al Centro de Detención, en las reuniones impulsadas por el CELS y en los encuentros en la Comisión Bicameral, donde migrantes que no pertenecían a organizaciones de migrantes más tradicionales y de más larga trayectoria,

\footnotetext{
3 En términos generales, mediante el DNU se amplían las causales para el rechazo, cancelación de la residencia y expulsiones ya que se incluyen delitos menores y sin condena firme; se reducen los plazos para ejecutar órdenes de expulsión a costa del derecho de defensa y debido proceso de la persona migrante; ante una orden de expulsión, se limitan los supuestos en los que puede alegarse el derecho a la reunificación familiar y el arraigo social y se recorta el acceso a la Comisión del Migrante -órgano encargado de la defensa pública ante órdenes de expulsión- solo a las personas que puedan demostrar "carencia de medios económicos" (Galoppo, 2017, p. 146-147).

4 Los DNU que dicta el Poder Ejecutivo son revisados por la Comisión Bicameral Permanente la cual debe expedirse sobre la validez o invalidez de dicho decreto. La urgencia de las organizaciones en intervenir en esta instancia radica en que, presionar el rechazo del decreto en ambas Cámaras, implica su derogación.
} 
comienzan a ponerse en contacto y a compartir la necesidad de generar nuevas formas de participación. En reuniones informales en un comienzo y luego en asambleas de gran convocatoria se empieza a dar inicio al BTM y, más tarde, a la CMND.

\section{Dos procesos políticos para situar el surgimiento del BTM y la CMND}

El lanzamiento oficial del BTM fue en noviembre del 2017 aunque, desde febrero, ya se realizaban actividades de protesta bajo el nombre Paro Migrante. Se conformó como un espacio político que en su construcción interna priorizó articulaciones entre organizaciones de migrantes y migrantes autoconvocados. La sanción del DNU 70 puede considerarse el punto de inflexión a partir del cual se decidió formar el BTM, ya que surgió como un instrumento de articulación política de migrantes que tenía como objetivos inmediatos su anulación y refutar los discursos xenófobos y criminalizantes del gobierno nacional y provincial. Sin embargo, a lo largo del 2017, surge la necesidad de consolidar al BTM como un espacio de representación política y social de migrantes que trabaje en torno a problemáticas que vayan más allá de las planteadas por el DNU 70. En este sentido, se conformaron diversas áreas de trabajo que apuntaron a abordar la cuestión migrante de manera integral y a trascender la coyuntura política. Por ejemplo, desde la comisión territorial se realizaron talleres de formación, en articulación con organizaciones sociales, con el objetivo de formar una Red de Consultorías Migrantes; se dictaron cursos de español para migrantes senegaleses $y$, desde el espacio de género, surge el colectivo feminista Ni una Migrante Menos. A su vez, el BTM busca posicionar a los migrantes como un sujeto político con capacidad de incidencia en la realidad social y política de Argentina y la región. Así, el BTM se involucra en diversas luchas que no se encuentran vinculadas a problemáticas especificas migrantes, como por ejemplo, la desaparición de Santiago Maldonado; el rechazo a gobiernos como el de Bolsonaro o de cumbres como la del G20, la criminalización de la protesta, la reforma previsional, las políticas de recorte presupuestario y los pedidos por Memoria, Verdad y Justicia y por la legalización del aborto seguro y gratuito, entre otras.

Como parte de las iniciativas del BTM se decide impulsar, en enero de 2018, la CMND como una plataforma política y un espacio amplio de articulación donde confluyan organizaciones de migrantes, para migrantes (organismos de derechos humanos, de asistencia social a migrantes, grupos de investigación), organizaciones sociales y partidos políticos. En sus comienzos formaban parte de la campaña organizaciones como CAREF, organizaciones civiles de migrantes como AMUMRA, partidos políticos de izquierda como el Polo Obrero y organizaciones sociales como la Federación de Organizaciones de Base, Frente de Organizaciones en Lucha, Frente Popular Darío Santillán, 
Movimiento Popular La Dignidad, Barrios de Pie, Unión de Trabajadores de la Tierra, entre otras. El BTM como impulsor de este espacio es el que asumió el rol de dinamizador y de coordinación y, junto con organizaciones sociales y partidos políticos de izquierda, son los que plasmaron la impronta en las formas en que se estructuró internamente la campaña y que tomaron las estrategias de acción.

Ahora bien, para comprender el surgimiento de organizaciones como el BTM y de espacios de articulación como la CMND, es necesario atender a un doble proceso vinculado, por un lado, a las trasformaciones en las organizaciones de migrantes de la mano de jóvenes migrantes e hijos de migrantes y, por otro lado, a los cambios que se producen en los movimientos sociales constituidos por organizaciones de trabajadores desocupados y excluidos. Este doble proceso proporciona nuevas estructuras de organización, visiones y formas de hacer y pensar la política, centrales para comprender las reconfiguraciones de las luchas migrantes.

En relación al primer proceso es importante señalar que la conformación del BTM es producto del accionar de jóvenes migrantes e hijos de migrantes que deciden constituir nuevos espacios de organización debido a que plantean una distancia crítica respecto a las visiones, alianzas y estrategias de ciertos dirigentes históricos y de asociaciones de migrantes más tradicionales, muchas de las cuales participaron de las luchas por la Ley de Migraciones 25.871. Esta relación conflictiva es para Gavazzo (2018) la muestra de un recambio generacional en las propias comunidades políticas migrantes, que llevó a estos jóvenes a cuestionar las formas de organización de sus predecesores. Este distanciamiento se vincula a que estos jóvenes asumen nuevas perspectivas de construcción y formación en política como parte de los procesos de politización de las juventudes acontecido en la Argentina y en varios países de la región, en las últimas dos décadas (Gerbaudo Suárez, 2018, p. 222). Esto implicó que, tanto en sus países de origen como en los de llegada, se involucren en diversas experiencias de organización, de gran influencia para la configuración del $\mathrm{BTM}^{5}$.

En este sentido, las trayectorias de militancia de estos jóvenes, muchos de los cuales llegan al país luego de 2007, se encuentran cercanas a las de las organizaciones sociales y partidos políticos de izquierda que se consolidaron en Argentina luego de la crisis de 2001. A diferencia del contexto de surgimiento de las organizaciones de derechos humanos y de las organizaciones de migrantes tradicionales, estas organizaciones son producto de una crisis de

\footnotetext{
5 Por cuestiones de espacio no se profundizará en las experiencias de organización política de los jóvenes migrantes en los países de origen si bien consideramos que éstas se entrelazan con las tradiciones políticas organizativas de Argentina y se vuelven centrales para comprender al BTM.
} 
representatividad del sistema de partidos tradicionales de Argentina y de una crisis de legitimidad de la democracia liberal como canal de inclusión social y económica, lo que imprimió una impronta destituyente a su forma de pensar la política. Esto llevó a que estas organizaciones planteen espacios de disputa "por fuera" del Estado; prioricen el trabajo territorial y desarrollen canales extra institucionales para desarrollar su actividad reivindicativa (aunque tensionados entre la confrontación y la negociación con el Estado); le otorguen gran centralidad a los mecanismos deliberativos asamblearios y horizontales; se definan como parte de un nuevo sujeto social como parte del movimiento piquetero formado por trabajadores desocupados y excluidos y plantean reivindicaciones en el marco de las críticas al sistema capitalista neoliberal ${ }^{6}$.

Es necesario señalar que el vínculo que existe entre los integrantes del BTM y las organizaciones sociales y partidos de izquierda es heterogéneo ya que, si bien algunos de ellos formaban parte de estas organizaciones, otros no lo hacían de manera orgánica. Sin embargo, la mayoría de estos jóvenes participaban, al momento de conformar el BTM, de experiencias de organización que tienen como práctica y horizonte político la convergencia con las luchas desplegadas por las organizaciones sociales y partidos políticos de izquierda. Por ejemplo, entre los años 2010 y 2015, conformaron diversas agrupaciones orientadas a las problemáticas de sus países de origen como el "Congreso de los Pueblos Capitulo Argentina" que sigue el conflicto armado y las negociaciones de Paz en Colombia; la "Asamblea de Mexicanxs en Argentina", contra la militarización de la sociedad mexicana y la corrupción estatal en la guerra contra el narcotráfico; el "Movimiento Centroamericano 2 de Mayo" en la defensa del medio ambiente y los derechos de los pueblos indígenas integrada por jóvenes ecuatorianos, salvadoreños y hondureños; el "Movimiento 138" en rechazo a los procesos de ruptura democrática en Paraguay; "Simbiosis Cultural" y "Generación Evo" formadas por jóvenes bolivianos y la "Asamblea de Exiliados X la Educación de Mercado" convocada para luchar contra la privatización de la educación en Chile, entre otros espacios (Gerbaudo Suárez, 2018, p. 226).

Un segundo proceso que es importante considerar para comprender la conformación del BTM y, principalmente, el impulso de la CMND, son los cambios que se producen en las organizaciones sociales y partidos políticos de izquierda constituidas por trabajadores desocupados y excluidos. Estas organizaciones que, como se señaló anteriormente, surgen a finales de los años noventa como consecuencia de la crisis de los programas de reestructuración neoliberal, se encuentran integradas en una gran proporción por migrantes. En el contexto de surgimiento de estas organizaciones, los migrantes se incorporaron

6 Esta caracterización se realiza a partir de los aportes de Natalucci (2011) bajo lo que denomina la gramática autonomista y la gramática clasista de las organizaciones sociales y partidos políticos de izquierda. 
al movimiento de trabajadores desocupados dejando en un segundo plano su condición e identidad migrante. Esto se debió a que cambiaron su modo de intervención en el espacio público ya que las demandas por alimento, vivienda y trabajo relegaron los reclamos específicos migrantes. Luego de la crisis del 2001, los funcionarios que en los años noventa encabezaron campañas xenófobas, dejaron de hacer referencia a los migrantes ya que era insostenible el relato que los culpabilizaba por el desempleo y el deterioro de los servicios de salud y educación (Grimson, 2006, p. 90-91). El ciclo político que se abre luego de la sanción de la ley 25.871 no interpeló a estas organizaciones ya que los programas de regularización, las políticas de ampliación de derechos a migrantes y la "retórica de la inclusión" amortiguaron el impulso de demandas que giren en torno a cuestiones específicamente migrantes.

Esta situación se modifica cuando la migración se convierte en un asunto político y comienza a tomar visibilidad, en el año 2016, en la agenda del gobierno de Cambiemos. El impulso de políticas migratorias regresivas y la puesta en circulación de relatos estigmatizantes y criminalizantes de la migración interpelaron a las organizaciones sociales y a los partidos políticos de izquierda. Es así que, la condición migrante se visibiliza y emerge como una problemática dentro de estas organizaciones. Son los migrantes quienes, por un lado, disputan al interior de sus organizaciones sociales la incorporación de la cuestión migrante e impulsan espacios de reflexión y debate $^{7}$ y, por otro lado, apuestan a construir espacios de articulación política que les permita visibilizar sus demandas específicas migrantes en el espacio público, como es la CNMD ${ }^{8}$.

\section{Trabajadores, asambleas y lucha en la "calle": elementos para pensar las nuevas configuraciones de las luchas migrantes}

Los dos procesos políticos que se describieron en el apartado anterior modifican las características que asumen las luchas migrantes en Argentina. Éstas no solo se van a inscribir en el marco general de las luchas llevadas adelante por el movimiento de derechos humanos o de las organizaciones de migrantes más tradicionales, sino que también van a entran en diálogo con las tradiciones políticas de las organizaciones sociales de trabajadores desocupados y excluidos y las experiencias políticas de los jóvenes migrantes e hijos de migrantes. Esto transforma no solo las estructuras de organización

Como parte de este proceso es interesante señalar como, en mayo del 2019, algunas organizaciones sociales que forman parte de la Central de Trabajadores de la Economía Popular (CTEP) impulsaron la creación de la Secretaria de Trabajadores Migrantes CTEP-Capital. En el mismo sentido, diversas organizaciones sociales de Córdoba capital, como la Federación de Organizaciones de Base y el Encuentro de Organizaciones, constituyeron asambleas migrantes para abordar problemáticas específicas a su condición.

8 Quienes participan de las reuniones de la CMND son los referentes migrantes de las organizaciones sociales y partidos políticos de izquierda y son los que asumen la palabra en las manifestaciones y actos públicos. 
y las estrategias de protesta sino también pone en cuestión las visiones y los vínculos que estas organizaciones establecen con el Estado. A continuación se identificaran los elementos novedosos presentes en las luchas migrantes a partir del surgimiento de organizaciones como el BTM y la CMND.

En primer lugar, se adoptan nuevas visiones y categorías identitarias que delinean nuevas estructuras de organización y ejes sobre los que se articulan las demandas de estas organizaciones. Un elemento central que distingue al BTM de las estructuras organizativas de las colectividades y organizaciones de migrantes más tradicionales, es que se construye como un espacio de confluencia entre migrantes de diversos orígenes nacionales. A diferencia de éstas -que privilegiaban la organización entre migrantes de un mismo origen nacional y entre las cuales existían rivalidades haciendo difícil la articulación de acciones que se mantengan en el tiempo- el BTM buscó mostrar la unidad de los migrantes y superar las diferencias internas. Para esto se recurrió a categorías de identificación que enfaticen sus similitudes y los unifiquen como la de "latinoamericanos" o "trabajadores" (Gavazzo, 2018, p. 153-154).

Se considera que estas categorías de identificación emergen de su experiencia junto a las organizaciones de trabajadores desocupados y excluidos, lo que ubica a las luchas migrantes en el horizonte político de estas organizaciones. El BTM al apelar a categorías como la de "trabajadores" incorpora a las luchas migrantes nuevas dimensiones de disputa ya que no solo reivindican su condición de migrantes sino que además articulan ésta condición con una identificación de clase. Reconocerse como trabajadores migrantes le permite al BTM inscribir sus demandas dentro de las luchas contra el sistema capitalista y, centralmente, cuestionar las formas de sujeción de la mano de obra al capital. Un eje central de sus luchas es visibilizar el lugar subordinado y precarizado que los migrantes ocupan en el régimen de trabajo. En este sentido, una de las primeras actividades fue la convocatoria a un Paro Migrante el 30 de marzo de 2017. A través de consignas como ¿Qué pasaría si Ixs migrantes paramos?, ¿Qué pasaría si lxs migrantes demostramos todo lo que aportamos a la sociedad?, los migrantes se afirmaron como "trabajadores/as" en su esfuerzo de contrapesar los discursos que los asociaban con la delincuencia.

De este modo, las reivindicaciones ya no van a ser solo codificadas a partir del lenguaje de derechos humanos o desde una perspectiva que, desde un enfoque cultural, refuerza la identidad nacional de los migrante, sino que se añade una nueva dimensión de clase en la que se asienten y articulan las luchas. Esta identificación de clase deja atrás viejas categorías procedentes de las organizaciones de derechos humanos como son la de ciudadanos y migrantes como sujetos de derechos $y$, a su vez, coloca en un segundo plano aquellas prácticas y formas de intervención política de las organizaciones de migrantes 
más tradicionales, centradas en la "difusión de su cultura" y la reivindicación del derecho a la diferencia cultural.

En segundo lugar, el BTM y la CMND modifican las alianzas y las relaciones con diversas instituciones estatales encargadas de la migración. Las tradiciones y prácticas políticas y organizativas del BTM y la CMND ponen en cuestión las estrategias de carácter institucional y legal que históricamente venían configurando las organizaciones de migrantes tradicionales y los organismos de derechos humanos y asistencia social a migrantes. Como ya se señaló, los activistas y las organizaciones sociales que conformaron el BTM y la CMND no apuestan, en una primera instancia, a una articulación institucional para la canalización de sus demandas, del mismo modo que, la formulación de sus reivindicaciones no busca codificarse en el lenguaje legal de las normativas migratorias. En otras palabras, el carácter destituyente prima sobre las formas instituyentes de hacer y pensar la política. Así, si bien estas organizaciones no descartan instancias de interlocución con el Estado, sí se modifica el lugar desde donde se lo interpela: no pretenden generar instancias de trabajo en conjunto en la elaboración o modificación de políticas migratorias sino más bien, estas instancias se entienden como espacios de negociación en la conquista de demandas concretas. Un ejemplo es el carácter que asumió la Mesa de diálogo con la DNM, en julio de 2019, la cual -luego de varias movilizaciones y concentraciones frente al edificio- se conformó con el objetivo de presentar una serie de exigencias a la DNM.

En relación con esto, en tercer lugar, el BTM y la CMND asumen nuevas estrategias de protesta. Para estas organizaciones la disputa debe ser llevada a la "calle", es decir, el BTM y la CMND privilegian las movilizaciones públicas para el reclamo de sus demandas y reivindicaciones. Esto no supone el rechazo de las estrategias de intervención institucional o aquellas que contemplan vías judiciales, pero si es diferente el peso y la importancia que se le dan en la articulación y configuración de las luchas. Mediante movilizaciones denominadas Migrantazos y Paros Migrantes, se configuran nuevas formas de intervención en el espacio público en relación a la cuestión migrante. Entre los años 2017 y 2019 se realizaron numerosas movilizaciones de reclamo y conferencias de prensa en la legislatura porteña, que tuvieron gran impacto y visibilidad pública, logrando instalar una serie de demandas al gobierno nacional, como por ejemplo: el no cobro por el uso de servicios de salud y educación; el no aumento de las tasas migratorias; el cese de las expulsiones arbitrarias; la modificación del sistema de radicación RADEX; la interrupción del aumento de las tasas migratorias; el fin de las demoras en los turnos para realizar los trámites de radicación y de la violencia policial, entre otras. Estas actividades fueron acompañadas de una nueva estrategia comunicacional centrada en el uso de diferentes redes sociales (Facebook, Instagram y Twitter). A través de éstas se 
convocó a las actividades y reuniones abiertas, se difundieron movilizaciones y conferencias de prensa y se realizaron campañas de apoyo a sus reclamos, lo que les permitió llegar a más cantidad de personas y ganar mayor visibilidad y apoyo público.

Por último, la construcción del BTM y la CMND muestra otra serie de rupturas con las experiencias de organización previas, ya que se modifica la relación que históricamente mantuvieron las organizaciones de migrantes y las de derechos humanos y de asistencia social a migrantes. Actualmente no solo hay un mayor esfuerzo de coordinación entre las organizaciones de migrantes que luego definen las articulaciones con los organismos de derechos humanos (Gerbaudo Suarez, Sander, 2017, p. 10) sino que son los espacios políticos integrados por migrantes los que asumen protagonismo y ganan autonomía al momento de plantear las estrategias de acción en el espacio público, al marcar las agendas y ejes de las lucha y asumir y definir los vínculos y formas de relación con el Estado. Los migrantes "toman la palabra" en las instancias de negociación con el Estado, en los organismos nacionales e internacionales de denuncia y en las manifestaciones públicas, desplazando el rol que ocupaban los "especialistas" pertenecientes a los organismos de derechos humanos y asistencia social a migrantes. Si bien las conexiones y articulaciones entre estas organizaciones son múltiples, ahora se dan en un marco de paridad lo que desarma la centralidad que asumían los organismos de derechos humanos en la articulación de las luchas.

\section{A modo de cierre}

La emergencia de nuevas organizaciones de migrantes (BTM) y espacios de articulación política (CMND) abren un escenario inédito en la configuración de las luchas migrantes en Argentina. A las experiencias de organización y lucha que llevan adelante las organizaciones de derechos humanos y las organizaciones tradicionales de migrantes se suman novedosos espacios de organización que incorporan nuevas estrategias de lucha, visiones y formas de organización e intervención en el espacio público. En este sentido, en este trabajo se intentó poner en dialogo, no solo las experiencias políticas organizativas, que desde mediados de los años noventa, llevan adelante organizaciones de y para migrantes, sino también atender a las transformaciones en los movimientos sociales constituidos por organizaciones de trabajadores desocupados y excluidos, como así también, el surgimiento de nuevas formas de organización de jóvenes migrantes e hijos de inmigrantes. El entramado de las luchas migrantes con nuevas tradiciones políticas pertenecientes a estos dos últimos procesos transformó las visiones, las estructuras de organización, las estrategias de protesta y las relaciones que organizaciones como el BTM y la CMND establecen con el Estado. Estas reconfiguraciones de las luchas 
migrantes imprimen nuevas características al campo político de la migración en Argentina.

Como se intentó mostrar, el surgimiento de categorías identitarias vinculadas a las luchas del movimiento de trabajadores desocupados y de aquellas relacionadas a las de jóvenes migrantes e hijos de migrantes, incorporó nuevas dimensiones de disputa y visiones en las cuales se enmarcan las luchas migrantes. De igual forma, si bien las estrategias institucionales y legales tuvieron gran centralidad, entre los años 2016 y 2019, asumieron mayor protagonismo las estrategias de reclamo y visibilización de las demandas en el espacio público mediante la movilización y la disputa en "la calle", lo que modificó, a su vez, la relación que se estableció con las instituciones estatales encargadas de la migración. Por último, un elemento clave es la transformación del vínculo histórico que mantuvieron las organizaciones de migrantes y para migrantes. Las relaciones entre estas organizaciones fueron muchas y diversas en diferentes coyunturas históricas, sin embargo, la conformación de espacios amplios de articulación, la mayoría de las veces, decantaron en espacios diferenciados de acción. La conformación de la CMND y el dinamismo que imprime a ésta el BTM, muestra una novedad respecto al protagonismo que asumen las organizaciones de migrantes en los procesos de articulación de las luchas. En el periodo comprendido entre los años 2016 y 2019 se produce una mayor articulación entre las organizaciones de y para migrantes, lo novedoso radica en que ahora son las organizaciones de migrantes quienes proponen espacios políticos de articulación, quienes definen las estrategias de protesta y quienes se posicionan como interlocutoras del Estado y marcan la agenda de debate y disputa en torno a la cuestión migrante, en una relación de igualdad, con las organizaciones de derechos humanos, de asistencia social a migrantes y los espacios académicos.

\section{Referencias bibliográficas}

ALONSO, Luciano. El surgimiento del movimiento argentino por los derechos humanos en perspectiva comparada. Páginas Revista Digital de la Escuela de Historia, v. 1, n. 1, p. 97-108, 2008.

BADARÓ, Máximo. La conciencia y la ley: la cuestión migratoria en las prácticas de agencias estatales y organismos no gubernamentales en la Ciudad de Buenos Aires. In: GRIMSON, Alejandro; JELIN, Elizabeth (comps.). Migraciones regionales hacia la Argentina. Diferencia, desigualdad y derechos. Buenos Aires: Prometeo, 2006, p. 207-235.

CAGGIANO, Sergio. La cuestión migratoria: reconocimiento de derechos, identidades nacionales y (ausencias de) género. In: JELIN, Elizabeth; CAGGIANO, Sergio; MOMBELLO, Laura (eds.). Por los derechos. Mujeres y hombres en la acción colectiva. Buenos Aires: Nueva Trilce, 2011, p. 47-77. 
CANELO, Brenda; GAVAZZO, Natalia; NEJAMKIS, Lucila. Nuevas (viejas) políticas migratorias en la Argentina del cambio. Si Somos Americanos. Revista de Estudios Transfronterizos, v. 18, n. 1, p. 150-182, 2018.

CELS. Centro de Estudios Legales y Sociales. Argentina. Avances y asignaturas pendientes en la consolidación de una política migratoria basada en los derechos humanos. Buenos Aires: CELS, 2011.

CORREA, Violeta. El papel de la sociedad civil en los derechos humanos de los migrantes. Reunión de expertos sobre población, desigualdades y derechos. Santiago de Chile: CEPAL-CELADE, 2006, p. 1-11.

COURTIS, Corina; PACCECA, María Inés. Migración y derechos humanos: una aproximación crítica al 'nuevo paradigma' para el tratamiento de la cuestión migratoria en la Argentina. Revista Jurídica de Buenos Aires. Número especial sobre Derechos Humanos, p. 183-200, 2007.

DE GENOVA, Nicholas; MEZZADRA, Sandro; PICKLES, John. New Keywords: Migrations and Borders. Culture Studies, v. 29, n. 1. p. 55-87, 2015.

DOMENECH, Eduardo. La visión estatal sobre las migraciones en la Argentina reciente. De la retórica de la exclusión a la retórica de la inclusión. In: DOMENECH, Eduardo (comp.). Migración y política: el Estado interrogado. Procesos actuales en Argentina y Sudamérica. Córdoba: Universidad Nacional de Córdoba, 2010, p. 21-69.

DOMENECH, Eduardo; BOITO María Eugenia. Luchas migrantes en Sudamérica: reflexiones críticas desde la mirada de la autonomía de las migraciones. In: CORDERO, Blanca; MEZZADRA, Sandro; VARELA, Amarela (coords.). América Latina en movimiento. Autonomía de la migración, fronteras y nuevas geografías de lucha. Madrid: Traficantes de Sueños/Tinta Limón, 2019.

GALOPPO, Lucía. Necesidad y Urgencia en la protección de los derechos de las personas migrantes. El amparo presentado por las organizaciones de la sociedad civil ante el DNU 70/2017. Revista Temas de Antropología y Migración, n. 9, p. 143-153, 2017.

GAVAZZO, Natalia. Jóvenes migrantes e hijos de migrantes latinoamericanos en Buenos Aires: una generación en movimiento. Confluenze, v. X, n. 1, p. 131165, 2018.

GERBAUDO SUÁREZ, Débora; SANDER, Joanna. Cuando los migrantes se organizan, las categorías se mueven. Discusiones teóricas para replantear el abordaje etnográfico de las prácticas políticas transnacionales. Ponencia presentada en la XII Reunión de Antropología del Mercosur, Misiones, Argentina, 4 al 7 de diciembre, 2017.

GERBAUDO SUAREZ, Débora. Juventudes latinoamericanas en Buenos Aires. Luchas migrantes y configuraciones transnacionales de lo local. Argumentos, v. 15, n. 1, p. 213-234, 2018.

GRIMSON, Alejandro. Nuevas Xenofobias, nuevas políticas étnicas en la Argentina. In: GRIMSON, Alejandro; JELIN, Elizabeth (comps.). Migraciones regionales 
hacia la Argentina. Diferencia, desigualdad y derechos. Buenos Aires: Prometeo, 2006, p. 69-97.

JELIN, Elizabeth. Los derechos humanos y la memoria de la violencia política y la represión: la construcción de un campo nuevo en las ciencias sociales. Cuadernos del IDES, n. 2, p. 3-27, 2003.

JELIN, Elizabeth. Migraciones y derechos: instituciones y prácticas sociales en la construcción de la igualdad y la diferencia. In: GRIMSON, Alejandro; JELIN, Elizabeth (comps.). Migraciones regionales hacia la Argentina. Diferencia, desigualdad y derechos. Buenos Aires: Prometeo, 2006, p. 47-68.

MARDONES, Pablo. La incorporación de los migrantes a la agenda de los derechos humanos en la Argentina. Buenos Aires: CELS, 2005.

MEZZADRA, Sandro. Capitalismo, migraciones y luchas sociales. La mirada de la autonomía. Nueva Sociedad, n. 237, p. 159-178, 2012.

NATALUCCI, Ana. Entre la movilización y la institucionalización. Los dilemas de los movimientos sociales (Argentina, 2001-2010). Polis (En Linea), n. 28, p. 1-22, 2011.

PENCHASZADEH, Ana Paula; GARCÍA, Lila. Política migratoria y seguridad en Argentina hoy: iel paradigma de derechos humanos en jaque? URVIO, Revista Latinoamericana de Estudios de Seguridad, n. 23, p. 91-109, 2018.

PEREIRA, Andrés. Política Migratoria, derechos humanos y seguridad en Argentina: el Humanitarismo en disputa 1990-2005 (Tesis Doctoral). Universidad Nacional de Córdoba, Facultad de Ciencias Sociales, Centro de Estudios Avanzados, 2017. 